\title{
Study on Indoor Multimedia Teaching Platform and Work Mode of College Instructors based on Cloud Computing
}

\author{
Yongxia Hao \\ Xi'an Physical Education University, Xi'an 710068, China \\ *blzy1163@163.com
}

\begin{abstract}
The rapid development of digital technology promotes the media industry, which makes the contemporary mass media has been widely used. In this paper, the author study on smart multimedia classroom and work mode of college instructors based on cloud computing. Cloud computing has changed the traditional PC centric computing model, all of the program data are all hosted in the cloud server. With the application of the social media platform, the instructor can transfer the education information to the college students at any time and at any place. Social media is interactive for college students to browse educational information; students can also use instant messaging tools. This interaction model can avoid the didactic education; and could enhance the recognition and trust of college counselors.
\end{abstract}

Keywords: Intelligent classroom, Multimedia platform, College instructors, Social media, Psychological guidance

\section{Introduction}

With the development of modern science and technology in the process of rapid development of digital technology, communication technology has promoted the rapid rise of the media industry, which makes the contemporary mass media has been widely used, has a profound influence on the social life[1]. The network media is by people's love, according to the relevant statistical data, the network has become an indispensable public social life of information tools, more deeply penetrated into every aspect of social life[23]. Similarly, the new media is a dizzying speed to enter the University, into the campus, into all aspects of university teachers and students, especially the students' ideology, values, moral ideal has important influence. The rapid development of modern media, the ideological and political education has been hitherto unknown impact, how to deal with the influence of media on college students, how to carry out ideological and political education of college students in the new situation of the Internet media, is an urgent and tough task placed in front [4].

Ideological and political education of college students is based on team building, and the college students' Ideological and political education as the main team, directly related to the success or failure of Ideological and political work of College students [5-6]. In the face of increasingly severe pressure on the network, the colleges are actively exploring and practicing the work mechanism of network counselors work. Social media is to rely on the network communication and digital communication technology, users can borrow the established extensive contacts, get all kinds of information and services, and have great participation and interactive online media platform, micro-blog, QQ, WeChat, renren.com is the typical representative[7]. Social media is the inevitable trend of the development of science and technology, to create a virtual space, convenient for rich students, to students' learning and life, ideology has brought about great changes also 
make counselor education environment more complicated, education challenges and opportunities exist.

The multimedia teaching is the trend of education informatization and the direction of the future, while the education informationization is the only way which must be passed to realize digital campus and the modernization of education, which need the whole society into a huge financial and human resources, planning and design can provide support for the multimedia teaching management system for university teaching, the real demand is strong[8]. At this time, the emergence of cloud computing for the establishment of network teaching platform for colleges and universities, the integration of teaching resources, to carry out the digital campus construction provides a new network environment and solutions. The construction of multimedia teaching management system of cloud computing technology into the existing software and hardware environment, the integration of universities, optimize the teaching management, and collaboration services, the multimedia teaching management system platform with strong function, safe and reliable operation, can complete the workload, has very important practical significance to research and practice of Multimedia teaching platform to carry out in Colleges and universities.

\section{Cloud Computing and Multimedia Platform}

\subsection{Cloud Computing}

In today's world, with the continuous development of network technology, network information and services have been everywhere, all over the world. Due to the "cloud computing" model will be tens of thousands of servers in a server cluster to provide services, in addition to providing the original function, but also enriched the application, owned by the local computer software services, data storage and other functions, to solve the original distributed heterogeneous difficult processing and data security issues, hardware updates frequently, massive data retrieval difficult problem, has had a huge impact on the traditional network service mode. For a time, cloud storage, cloud security, cloud engine, cloud services, and so have to enter our user's vision. Cloud computing appears to make the user experience more convenient and intelligent. Users no longer need to worry about data loss, virus damage to the system, but also do not need to install new applications or frequently upgrade the original application software. Cloud computing has changed the traditional mode of computing the PC as the center, all of the program data are all hosted in the cloud server. Relatively speaking, the computing power and storage requirements of the client device decreases, users simply through a personal computer or mobile phone and other terminal equipment to access the Internet, and pay the corresponding fees according to the need, you can use a large whenever and wherever possible and scalable cloud resource service. 


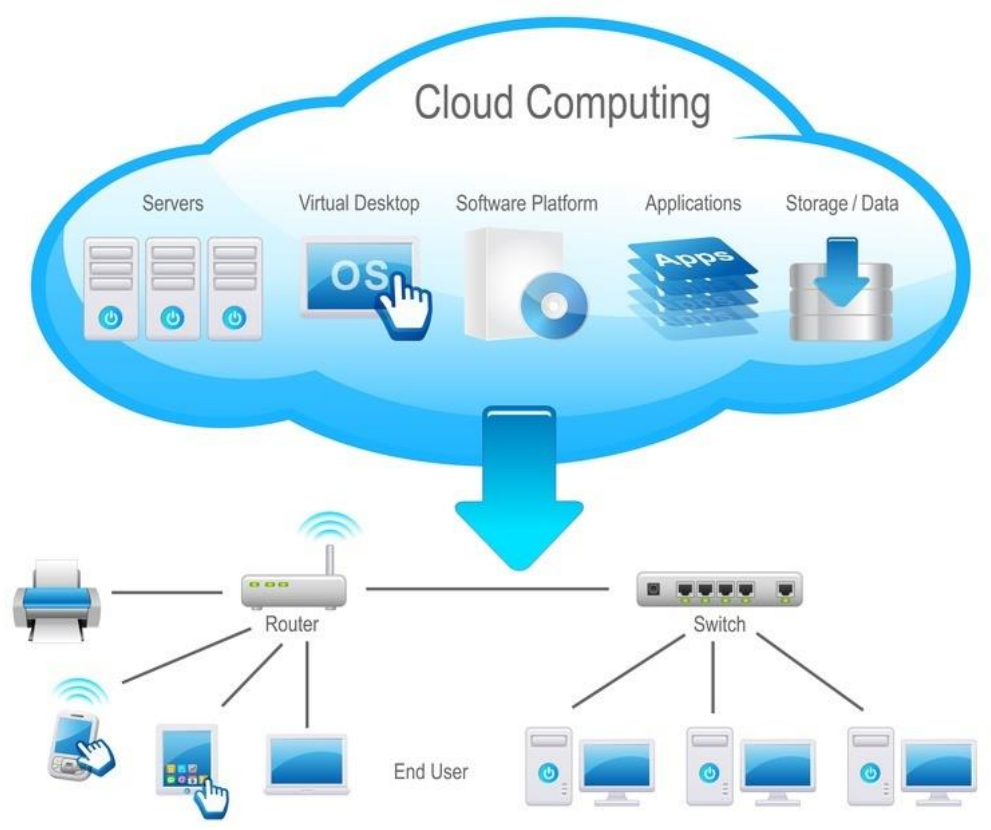

Figure 1. Cloud Computing

Cloud computing is a kind of thought, it is a kind of technology, and it is a kind of way. The emergence of cloud computing, its access and computing power, the traditional PC and application server centric application mode will change, also make the existing IT ecosystem changes greatly, users and providers and become the core role of the new ecological builders, and play different roles.

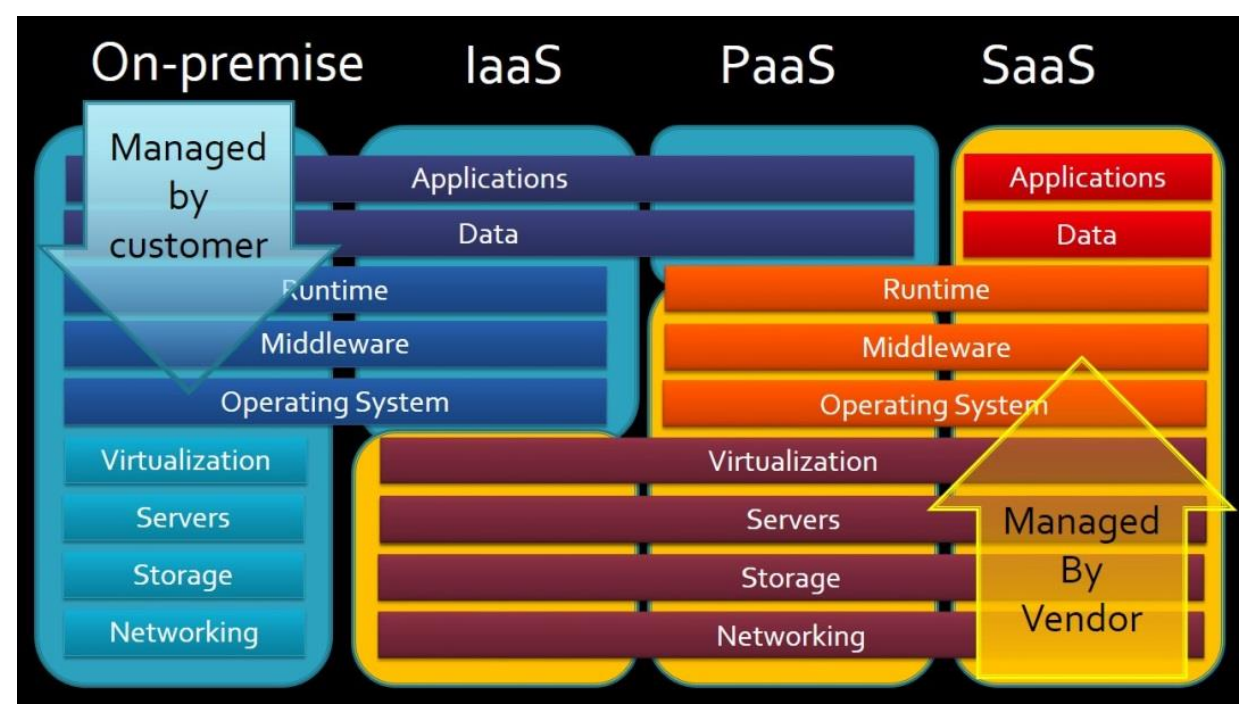

Figure 2. Cloud Computing Architecture

SaaS: SaaS is the service provider application software deployment in the cloud server, the user can use the terminal connected to the Internet, using the browser or client to connect cloud server access to software services, you can also order related software services according to their needs, and pay a fee. So as long as there is an internet terminal, the user can enjoy the time and place to enjoy the cloud services, cloud server hardware and software maintenance upgrades are managed by the vendor.

PaaS:PaaS is a cloud platform provides a development environment for the development needs of the enterprise, which can provide the specific needs of development 
in the cloud environment of Cloud Applications in the enterprise to pay for the cloud environment at the same time, the enterprises can also use specific program development platform to provide services for users, which is convenient to the resources service enterprise sharing between users. PaaS can provide the program development, application of database and server services, is the development of cloud application middleware platform.

LaaS:laaS is through the virtual technology to the cloud of a variety of hardware devices into a pool of resources, and in the form of services for customers to use, such as providing storage services and virtual server services, and so on. LaaS advantage is low cost, customers only need to pay the rent of the appropriate services, you can use the cloud technology virtual processor, memory and other hardware devices, compared with the traditional mode of cost significantly reduced.

\subsection{Multimedia Teaching Cloud Platform}

The multimedia teaching platform based on the cloud environment to the existing teaching platform and campus network, establish a cloud computing center, through the hardware and software environment of teaching resources management platform and SaaS application cluster method. Among them, the cloud computing center provides data encryption and data storage service platform for teachers and students, the user can use the terminal equipment, the original teaching resource is accessed through the campus network, you can also get cloud platform services through the cloud platform unified interface, realize the sharing of old and new data platform. The plan of university multimedia teaching platform based on cloud computing is shown in Figure 3:

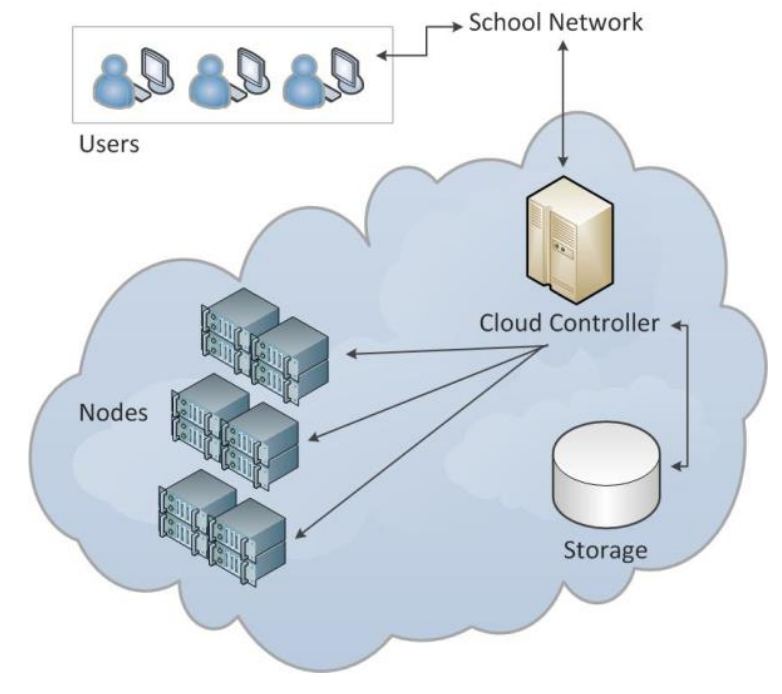

Figure 3. Multimedia Cloud Computing Platform

At present, colleges and universities generally have the construction of such as excellent courses, online training, professional resource base and other small system platform. In order to reduce the maintenance cost, make full use of original data, universities can according to their own actual teaching resources according to the data to develop a unified data format finishing each platform set up organizational structure and professional courses, to convert the data of all the data platform, cloud computing platform and the platform can be carried out online or offline synchronization, realize data backup in the cloud computing center, convenient for users to query at the same time, guarantee the unity and safety of teaching resources data. In addition, the sub teaching platform can not only provide individual service for the users, but also can share the teaching resources through the data interface and the cloud platform. 
The entire platform to provide users with a unified access to the entrance, the user to use the Internet terminal, according to the needs of the identity, according to the needs of the professional courses or institutions set up to select the relevant learning services. The platform independent code and database code for each specialty, teaching resources curriculum and related professional association, users can rely on cloud computing ability of the powerful platform, fast and accurate retrieval of all kinds of curriculum and teaching resources, improve the effect of online learning. For the more important function of remote teaching, the school through the campus LAN or carry out centralized room teaching mode; for virtual LAN users outside the campus by use of cloud computing (VLAN) technology, according to the different teaching object, construct different VLAN, users do not rigidly adhere to the physical position, also enjoy the cloud computing platform to bring easy and convenient. The multimedia teaching platform in cloud environment using the SaaS model, centralized maintenance data platform, the platform shielding school resource access and management, implement the massive teaching resource construction, sharing, data intensive embodies the advantages of the system, completely solve the original teaching platform data specifications are not unified, the problem of data security risks and the low efficiency caused by imperfect system.

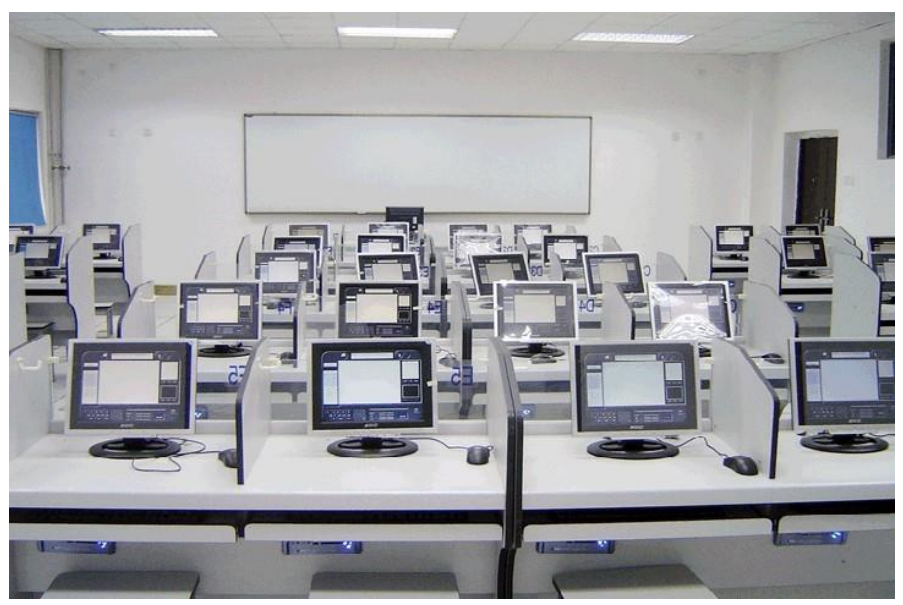

Figure 4. Multimedia Teaching

\section{The Work of Instructors in the Social Media Environment}

\subsection{Social Media}

The so-called media, in general, is the carrier of the spread of information, and is a form of communication functions of the entity. Traditional media refers to newspapers, magazines, radio, television and other carriers and their distribution agencies, with the development of science and technology, social media came into being. Social media is the concept of communication, which is not only a general designation of information communication, but also a kind of network application and platform. The various types of social media, including QQ, MSN, blog, micro-blog, Wikipedia, Baidu encyclopedia, podcast, forums, social networking, etc.. According to the characteristics and functions of the difference, this paper will be divided into the following types of social media:

1) Instant messaging: social media for real-time information exchange through the Internet, the main representative is QQ, MSN, Fetion and WeChat.

2) Self presentation category: by means of some specific forms, such as text, pictures, video and audio to achieve self display, good feelings, feelings of social media sharing of resources, the main types include blogs, QQ, micro-blog and WeChat space circle of friends. 
3) Social networking sites: refers to the Internet application services that help people build social networks, expand their interpersonal relationships, and interact with the Internet. In foreign countries, the main representative is Facebook, the famous domestic social networking sites have all the network, and the country's most influential online interactive community classes, etc..

4) Free discussion class: the main representatives of the famous social forum such as Tianya forum, Xicihutong, Baidu Post Bar, had now become fashionable for a time in BBS to enter the mature stage of development.

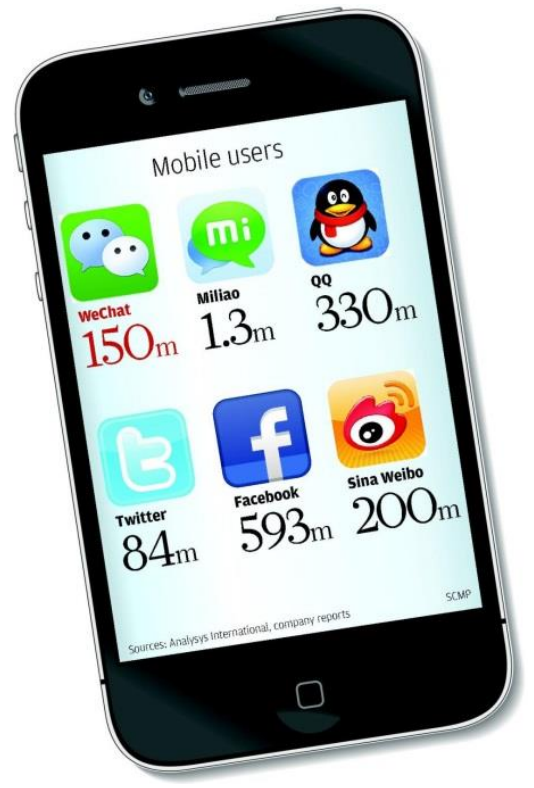

Figure 5. Social Media

Characteristics of social media:

1) Openness: the era of traditional media information transmission has a strict "mining editing system, and there are so many limitations of communication technology, information is limited in a narrow range of areas of a country, in the global communication did not really realize information"'". While social media has the information production and communication mode of freedom, as well as advanced digital communication technology, establish and maintain the information transmission and acquisition, the relationship can transcend geographical fan Benedict, more efficient and open resource sharing.

2) The civilian population: social media reflects the user's subjective status, all of which can be both the recipient and as a communicator, able to complete a series of processes such as self creation, self editing, self dissemination, self consumption and so on. And social media platform to achieve the information of the "flat" spread, everyone has an equal exchange of identity and status. The civilian nature of social media depends on the low cost of its use, the low threshold of operating technology, so everyone can have a display of self, participate in interactive media".

3) Interactivity: traditional media era of the relationship between the location is obvious, the spread of the point across, one to many, passive acceptance of information, the lack of information between the transmission of information, is a one-way, linear information dissemination. Social media has opened the "user centric" era, makes a point of communication, on the possible existence of frequent interaction, extensive and rapid spread between two or more persons and 
recipients, communicators can adjust their communication behavior based on recipient information feedback, the receiver can play the initiative change for the dissemination of information, all involved in the dissemination of the main interactive relationship exists between the free, go to the center of the.

4) Personalization: social media to adapt to the diversification of user needs and market diversification, can provide personalized service. In the aspect of information transfer time, through the social media platform "information push technology, control information according to the user preset transfer to social media terminal, users can also take the initiative to search the required information at any time, asynchronous information received. In the form of information transmission, social media can meet the requirements of user differences, users can choose according to their own preferences and needs of the media in the form of preference. In self display, as (micro) Bo Lord, home Jun, people can also choose a variety of templates, skin, background music and other design elements to decorate their own mold Bo home, QQ space, etc..

\subsection{Responsibilities and Core of the Work of the Counselors}

The counselor is the backbone of the ideological and political education and the healthy growth of college students mentor and guide, in the forefront of student work. It is the premise of the counselors to do a good job and develop the overall development of college students. With the change of the deepening reform of higher education and the needs of development of the college students, counselors work in the field continue to extend, but overall, their role and responsibilities for defining the basic work content can cover their commitments.

In all the staff responsible for the ideological and political education of college students from various job duties, but the scope of work division and specific requirements, for the rest of the staff, the ideological and political education is more and potential penetration, and the counselor is the backbone of College Ideological and political education. It can be seen from the historical evolution of the counselors system, the main line of the work of college counselors is ideological and political education. In the era of social media, college students in different degree problems such as lack of ideals and beliefs, facing the complicated network environment and realistic environment, college counselors have an important mission to strengthen the ideological and political education of College students. The instructor should correctly grasp the direction of time, varies from person to person to strengthen the political guidance, improve the ideological and political consciousness and moral cultivation of college students, help students' all-round development, right from wrong, the pursuit of lofty. The role of the role of counselors in the political quality and work ability to put forward a strict role requirement, counselors can play a good role; will be conducive to the ideological and political education work experience of the summary and the rule of exploration.

Contact the work of college counselor's practical, counselors can be divided into the following categories

- To carry out ideological and political education: ideological and political education is the original intention of the establishment of political instructors. The instructor is the daily ideological and political education of the perpetrators, organizers, guides, in the era of social media, especially by the extensive use of a variety of College Students' recognition and welcome the channels to help students establish a correct world outlook, outlook on life and values, to guide college students faith and faith; to help students develop good psychological quality and moral quality; through various forms of activities to talk, to help students clarify the ideological confusion and improve the spiritual realm. To do a thorough and meticulous work of Ideological and political education, the key lies 
in the combination of the characteristics of physical and mental development of college students, attention to the subjectivity of students, to grasp its focus and inner feelings, but also to grasp the education direction and take flexible combination, truly strengthening depth, implement.

- Organize educational activities: education is an important means of educating of counselors, counselors should give full play to the political advantage, position and organizational advantage, the overall strength, adhere to the "studentcentered" concept, mobilize and organize students to carry out various forms of educational activities. To guide the students to pursue higher goals, focus on the cultivation of moral quality and civilized behavior of college students; according to the school rules, according to the student's concerns, processing opinion relating to the maintenance of security and stability in Colleges and universities; to use the carrier and form new students strengthen the training and education of Party members and cadres, guidance the student Party branch and class construction, motivate the students to participate in the training of teachers and collective concept; to carry out regular exchanges, guide the students to create a good learning atmosphere, promote the common progress of the class. The effective development of all kinds of educational activities can create a good environment and order for educating people, which will help to promote the all-round development of college students.

- Provide students with the necessary services: "service is the optimization of enzyme" education and management ', to provide attentive service to college students, the ideological and political education in the service process and result, is the proper meaning of College Counselors' work duties in the. The service of educating people as counselors, reflects the "people-oriented" and "peopleoriented" concept and characteristics of colleges and universities, but also an inevitable choice to adapt to the development of the college counselors should put students as the guiding concept of sincere service, to carry out the work of College students. "Services" can be both transactional services daily, for example, to help solve practical problems, psychological problems of the students, provide poor funding channels, employment guidance practice, can also be through sincere and equal exchange, the students hit the deep thought, to change the right.

\section{Empirical Analysis}

\subsection{Questionnaire Investigation}

The dissemination of information on social media platform beyond time and space limitations, counselors can convey educational information to college students, vivid and easy to save, whenever and wherever possible, content, lasting effect, from the shallower to the deeper the students' ideology. Instructors can also understand the latest state of college students through social media, will extend the work of educating people to face to face and collective meetings and other occasions, the full range, the whole process, to carry out the work of educating people. Social media is interactive for college students to browse Counselor Education released information, can also use instant messaging tools and hidden communication expansion counselors, this interaction model can avoid the didactic education caused by the reverse psychology of college students, can enhance the recognition and trust of counselors in college students, counselors can make students obtain the feedback information thus, enhancing their education effect.

The questionnaire and interview investigation mainly focused on the following aspects: (1) the basic situation of College Students' use of social media and influence; (2) the basic situation of counselors by social media to carry out educational work; (3) College of 
counselors should carry out educational work in social media identity; (4) education problems of instructors carry out social media applications. A total of 400 questionnaires were distributed, 394 questionnaires were recovered, and the recovery rate was $98.5 \%$. The effective questionnaire was 363 , and the effective rate was $90.8 \%$. The results of the investigation, all instructors are used at least one social media work, $82.6 \%$ of the students think that counselors use social media is the highest frequency of WeChat, far more than other forms of social media proportion. In addition, $62.3 \%$ of the counselors and students are WeChat, friends; there are $35.8 \%$ of the counselors and college students are QQ friends or in the same group. On the whole, the application of social media in the counselor team is high.

\subsection{Social Media Assistance}

From a technical point of view, social media related technology system can be divided into two parts of hardware and software. First of all, from the hardware point of view, the current construction of campus network has been basically complete, most of the university library, faculty building, teaching building and student dining room are covered by the wireless network signal, coupled with the popularity of mobile phone, tablet computer and handheld Internet equipment, makes the students and counselors have the convenience of the Internet condition. Second, the software part of the social media refers to the computer related technologies involved in the social media. Currently, such as QQ, all networks and micro-blog, WeChat and other media computer architecture is in the Web2. 0 mode of mass data processing and storage technology. The technical level of social media to accommodate the content of education, education information transfer, and can meet the basic educational needs, provides a strong technical support for the application of social media to carry out educational counselors work.

From the functional perspective, social media has the educational communication function and network image construction function, function of dialogue, sharing resources function, promote the self promotion function, these are for counselors to carry out educational work provides a convenient. Zero and identity of social media restrictions, low economic cost and technical difficulty, and mobile terminal portability and popularity also makes the application of social media to carry out educational counselors work more maneuverability, can realize the whole process education. To carry out the educational work of counselors from the actual situation in recent years, according to the college counselors annual stories reported that there have been some counselors by social media to teach students effective examples, with technology innovation and technical support functions change rapidly, the development of social media will be constantly improved, creative application of socialization of counselors media to carry out educational work is feasible.

The application of social media to carry out education and guide the work of the traditional didactic way of Ideological and political education of subversion and innovation, social media content and various forms, strong interactivity, fit the "90" College Students' pursuit of individuality and equality of personality characteristics, welcome and support the students in the school. Questionnaire survey of college students in the embodiment of this view, as shown in Figure 2-3, for "I agree and support the counselors through social media education" this view, accounting for $79 \%$ of the overall investigation to "meet" and "fit" attitude of the college students, there are $76.4 \%$ of the students thought that the counselors use QQ, WeChat, micro-blog, etc. to carry out the renren.com education more vivid, more attractive. 


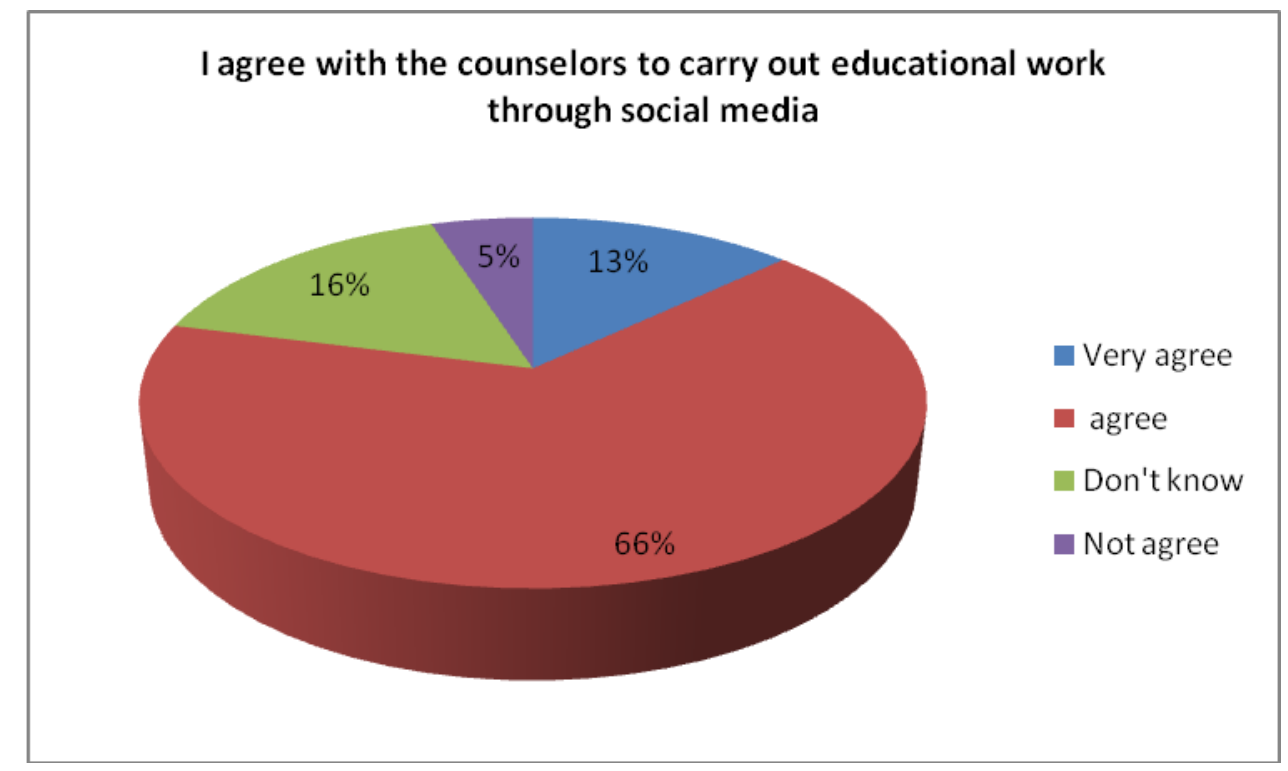

Figure 6. Identification of Counselors through Social Media Education

\subsection{The Application of Social Media in the Work of Instructors}

Although the use of social media instructors have been more common, the use of social media and social media is still floating on the surface, and did not play its due educational efficacy. The author made to interview some of the counselors can be seen, the focus of the work of counselors will mainly focus on the reality, only will complement the social media as a reality beyond the work do not essential. The survey data show that in answer to your instructor through the QQ group or group Fetion often give you send what problem ", select" accounted for $66.9 \%$ of the overall investigation, the campus class notice "of college students, far more than other options, that" instructor's social media platform is more like $73 \%$ of the overall investigation for all kinds of information notification platform "of college students;" said the counselor often by BBS, micro-blog, renren.com, QQ communicate with us, timely response to our questions or help respondents number less than a half, accounting for $40.5 \%$. These reflect only counselors use social media as a network information platform, the application of social media is mainly based on notice, such as sending a message to a low level, social media is limited to change the way of work, improve work efficiency, instructors lack consciousness deeply explore social media the characteristics and potential of the action, education and guidance for students to carry out the use of social media more insufficient.

Table 1. Counselors through the $Q Q$ group: Students Send Content

\begin{tabular}{|c|c|c|}
\hline Content & Number & Percentage \\
\hline Campus class notice & 237 & $66.5 \%$ \\
\hline Class, class attendance & 61 & $16.9 \%$ \\
\hline $\begin{array}{c}\text { Scholarship application and } \\
\text { publicity }\end{array}$ & 152 & $41.7 \%$ \\
\hline School lecture activities & 127 & $35.4 \%$ \\
\hline Party activists list & 105 & $29.7 \%$ \\
\hline $\begin{array}{c}\text { Words of encouragement } \\
\text { and concern }\end{array}$ & 46 & $11.5 \%$ \\
\hline Life and security alert & 87 & $23.2 \%$ \\
\hline Examination information & 204 & $57.7 \%$ \\
\hline
\end{tabular}


Table 2. Students' Expectation on the Application of College Counselors

\begin{tabular}{|c|c|c|}
\hline Content & Number & Percentage \\
\hline $\begin{array}{c}\text { Can give full play to the } \\
\text { initiative and participation }\end{array}$ & 141 & $38.5 \%$ \\
\hline $\begin{array}{c}\text { Can strengthen our } \\
\text { interaction and exchanges }\end{array}$ & 213 & $58.9 \%$ \\
\hline $\begin{array}{c}\text { Content can be updated } \\
\text { frequently }\end{array}$ & 110 & $31.7 \%$ \\
\hline Form can be more vivid & 135 & $38.4 \%$ \\
\hline $\begin{array}{c}\text { Close to the characteristics } \\
\text { and needs of students }\end{array}$ & 146 & $28.5 \%$ \\
\hline $\begin{array}{c}\text { Language and content } \\
\text { humor }\end{array}$ & 97 & \\
\hline
\end{tabular}

From the survey results, it seems that the use of social media to carry out the work of social science education, the main performance in: first, the use of a single form of media. The Counselor Group mainly uses the Fetion instant messaging tools such as (82.6\%), the use of other social media categories are not significant, such as counselors renren.com only $16.3 \%$ frequently used, and this kind of social networking site SNS and micro-blog is the network application of college students most favored, reflects the asymmetric status use of social media education and college counselors. Second, it is the lack of planning and targeted social media content. Counselors use human network, QQ space and other social media show class, the general lack of good content planning. Third, the instructor and the student's subjective and objective status is obvious, does not conform to the social media equality. Instructors to carry out educational work in social media applications, can not take the initiative to "weaken" the education status, $42.4 \%$ of the students think that counselors use social media to carry out the work when preaching color is heavy, to communicate with the students, lack of equal dialogue and democracy.

\section{Conclusions}

Social media has a great impact on Contemporary College Students' study, life, way of thinking and values, and it is also a challenge and opportunity for college counselors. As the main force of college education, counselors should face the situation and influence of social media in Contemporary College Students' Ideological and political education cause, the disadvantages and creative use of social media to carry out educational work. At present, the social media is the inevitable outcome of the development of the times and the progress of science and technology. Specifically, first of all, the counselor should be a comprehensive analysis of changes of social media brings, strengthen the understanding and study of characteristics and propagation of different types of social media, summed up the application of social media to enhance the effective ways and methods of education. Secondly, instructors should play in the inheritance and traditional education carrier function, educational function of continuous mining in social media, correspondence between College Students' personality, identify needs and social media features, creative use of social media, "blocking" into a "sparse", will become passive the mass media information to the community for screening and actively take the initiative to publish guidance. In short, the popularity of social media in college students and the enormous influence demands of college counselors should grasp this opportunity to advance the use of social media in education communication, avoid and overcome its shortcomings and negative effects, the effective carrier of social media as a new era of education. 


\section{References}

[1] R. A. Sabella, "School counselors perceived importance of counseling technology competencies", Computers in Human Behavior, vol. 26, (2010), pp. 609-617.

[2] N. R. Mastroleo and R. Turrisi, "Examination of posttraining supervision of peer counselors in a motivational enhancement intervention to reduce drinking in a sample of heavy-drinking college students", Journal of Substance Abuse Treatment, vol. 39, (2010), pp. 289-297.

[3] Z. Huang and M. Benyoucef, "From e-commerce to social commerce: A close look at design features", Electronic Commerce Research and Applications, vol. 12, no. 4, (2013), pp. 246-259.

[4] C. Zhang and X. Chen, "Use of Multimedia in Gross Infective Pathogen Experimental Teaching", Procedia Engineering, (2012).

[5] W. Dai and L. Fan, "Discussion about the Pros and Cons and Recommendations for Multimedia Teaching in Local Vocational Schools", Physics Procedia, (2012).

[6] R. Khansa, "Teachers' Perceptions toward School Counselors in Selected Private Schools in Lebanon", Procedia - Social and Behavioral Sciences, (2015).

[7] C. Krstev and A. Trtovac, "Teaching Multimedia Documents to LIS Students", The Journal of Academic Librarianship, vol. 40, no. 2, (2014), pp. 152-162.

[8] S. Jian-Hua and L. Hong, "Explore the Effective Use of Multimedia Technology in College Physics Teaching”, Energy Procedia, (2012).

\section{Authors}

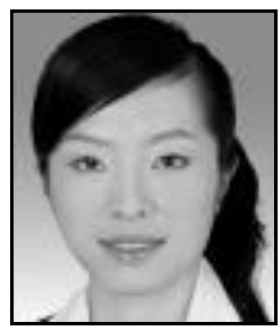

\section{Hao Yong Xia}

Current position, grades: the Lecturer of Xi'an Physical Education University, Xi'an, China.

Scientific interest: her research interest of College students' ideological and political work

Publications: more than 4 paper published

Experience: She has teaching of 9 years, has completed two Bureau level project, take part in two national level 